\title{
Identification and Localization of Gold Nanoparticles in Potassium Ion Pores: Implications for $K_{i r}$ Blockade
}

\author{
Chur Chin · Yu Shin Park
}

Received: February 20, 2016/Published online: April 28, 2016

(C) The Author(s) 2016. This article is published with open access at Springerlink.com

\begin{abstract}
Introduction: In our previous study, we found that negatively charged gold nanoparticles with spermidine have the potential of blocking inwardly rectifying potassium channels $\left(\mathrm{K}_{\mathrm{ir}}\right)$, both at the cellular and the tissue level.

Methods: For the purpose of the present study, we purified the cytoplasmic domain of the $\mathrm{K}_{\mathrm{ir}}$ 3.1 receptor from Escherichia coli. Using single particles with surface coating by transmission electron microscopy, we identified the gold nanoparticles at the cytoplasmic side of the human $\mathrm{K}_{\mathrm{ir}}$ channel.
\end{abstract}

Enhanced content To view enhanced content for this article go to www.medengine.com/Redeem/D6B4F060232 6E27C.

Electronic supplementary material The online version of this article (doi:10.1007/s40119-016-0060-8) contains supplementary material, which is available to authorized users.

\section{Chin $(\bowtie)$}

Department of Internal Medicine, Soon Chun Hyang University Bucheon Hospital, Bucheon, Kyunggi-do, Republic of Korea

e-mail: nanomedicin6@gmail.com

Y. S. Park

Center for Core Research Facilities, DGIST, Daegu

711-873, Republic of Korea
Results: Energy-dispersive X-ray spectroscopy showed the presence of the gold deposits in the cytoplasmic domain of the $\mathrm{K}_{\mathrm{ir}}$ receptor.

Conclusion: In conclusion, we could identify undecagold in the ion pore of the $\mathrm{K}_{\mathrm{ir}} 3.1$ channel in order to clarify its direct blocking effect in the $\mathrm{K}_{\mathrm{ir}}$ ion pore by undecagold.

Keywords: CryoEM; Cytoplasmic domain; $\mathrm{K}_{\mathrm{ir}} 3.1$; STEM

\section{INTRODUCTION}

Inwardly rectifying potassium channels $\left(\mathrm{K}_{\mathrm{ir}}\right)$ allow greater potassium ion $\left(\mathrm{K}^{+}\right)$flow into the cell than in the outward direction [1]. Nanoparticle penetration into the cells is an important process in drug delivery [2]. The penetration efficiency of nanoparticles may reach approximately 75\%, especially for those with anisotropic shapes or asymmetric surface decoration [3]. Nontoxic vitamin complexes such choline and spermidine have been used as composites containing nanoparticles [4]. The identification of new types of molecules targeting ion channels is of significant interest in biological research. Therefore, the aim of our 
work was to explore the mechanistic evidence of using novel materials such as undecagold, as ion channel blockers.

Gold nanoparticles can block the function of a channel by fitting into its pore and preventing further conformational change [5]. $\mathrm{K}_{\mathrm{ir}}$ channels are characterized by an extensive pore encompassing continuous transmembrane and cytosolic portions [6]. The key elements in G-loop gating transition involve the movement of the $\mathrm{N}$-terminus and C-linker that removed constraining intermolecular interactions. Negatively charged gold nanoparticles $(0.8 \mathrm{~nm})$ with spermidine are able to enter the cell and block the human $\mathrm{K}_{\mathrm{ir}}$ channel at its intracellular face [7]. The G loops are located towards the cytoplasmic site, playing a role in G-loop disrupted gating or inward rectification. The $G$ loop is the narrowest portion of the cytoplasmic domain in the $\mathrm{K}_{\mathrm{ir}} 3.1$ ion pore. This ion pore which has a diameter of approximately $8 \mathrm{~nm}$ has never been permeated by negatively charged undeca-gold [8]. The cytoplasmic ion-permeation pathways are occluded by four cytoplasmic loops that form a girdle around the central pore (G-loop). $\mathrm{K}_{\mathrm{ir}}$ channels, similar to other $\mathrm{K}^{+}$channels, have a tetrameric architecture, but, unlike other channels, have a long ion permeation pathway that consists of both a transmembrane and a cytosolic portion. The gating of $\mathrm{K}_{\mathrm{ir}}$ channels has been shown to involve the binding of divalent cations and polyamines to its cytoplasmic domain [9]. G-protein-gated $\mathrm{K}^{+}$channels $\left(\mathrm{K}_{\mathrm{ir}} 3.1-\mathrm{K}_{\mathrm{ir}} 3.4\right)$ control electrical excitability, regulating the heart rate by opening a G-loop gate in the cytoplasmic domain [10]. G loop crystal structures revealed two possible conformations of the cytoplasmic domains, one with a constricted cytosolic gate and another with a dilated G-loop gate. In cryo-electron microscopy (EM) images, undecagold-spermidine complex and negative charged gold nanoparticles $(0.8 \mathrm{~nm})$ bind ionically to two $\mathrm{NH}^{2+}$ and one $\mathrm{NH}^{+}$portions of the spermidine molecules. Spermidine $(1.2 \mathrm{~nm})$ is a suitable candidate for introducing gold nanoparticles into the cytoplasmic vestibule ( $3 \mathrm{~nm}$ diameter) of the receptors. Spermidine passes through the pore domain of the $\mathrm{K}_{\mathrm{ir}}$ channel with the incapacity for blocking other channels.

$\mathrm{K}_{\mathrm{ir} 3.1}$ normally functions as a heteromultimer with other members of the $\mathrm{K}_{\mathrm{ir}} 3$ family, whereas the chimera are homomultimer. The chimera used in this study might lack proper coupling between the cytoplasmic and transmembrane pores. However, single channel activity has yet to be demonstrated for the prokaryotic $\mathrm{K}_{\mathrm{ir}}$ channels. We have purified the cytoplasmic domain of the $\mathrm{K}_{\mathrm{ir}} 3.1$ receptor from $E$. coli (Figs. 1, 2, 3.).

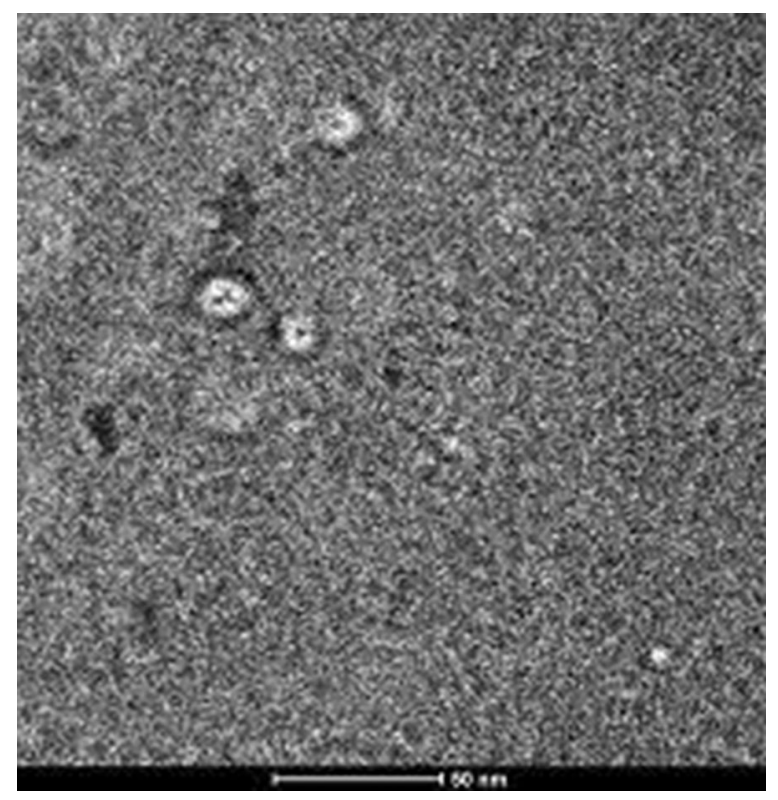

Fig. 1 Control ( $K_{i r}$ receptor cytoplasmic domain): a purified protein of the cytoplsmic domain of the $\mathrm{K}_{\mathrm{ir}}$ channel have collapsed lumens. $K_{i r}$ inward-rectifier potassium ion channel 

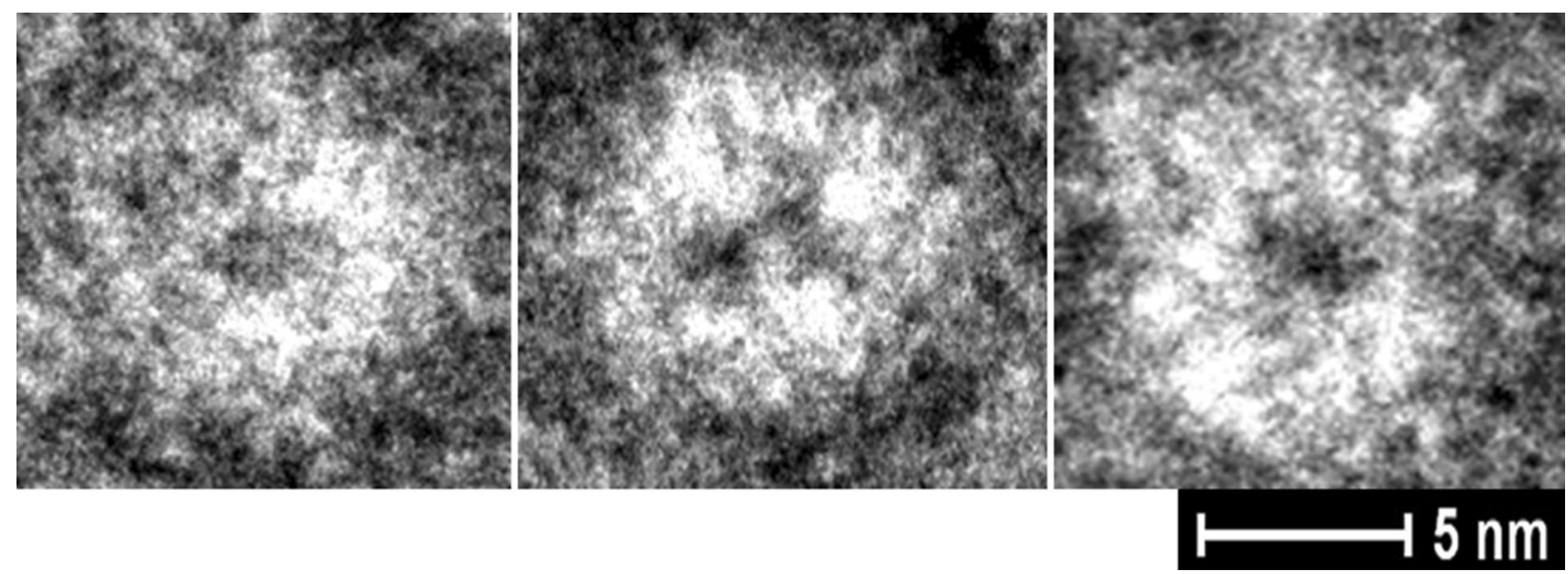

Fig. 2 Two dimensional TEM images show the tetramer of $\mathrm{K}_{\mathrm{ir}} 3.1$ cytoplasmic domain with collapsed lumen of the ion pore. TEM transmission electron microscopy, $K_{i r}$ inward-rectifier potassium ion channel

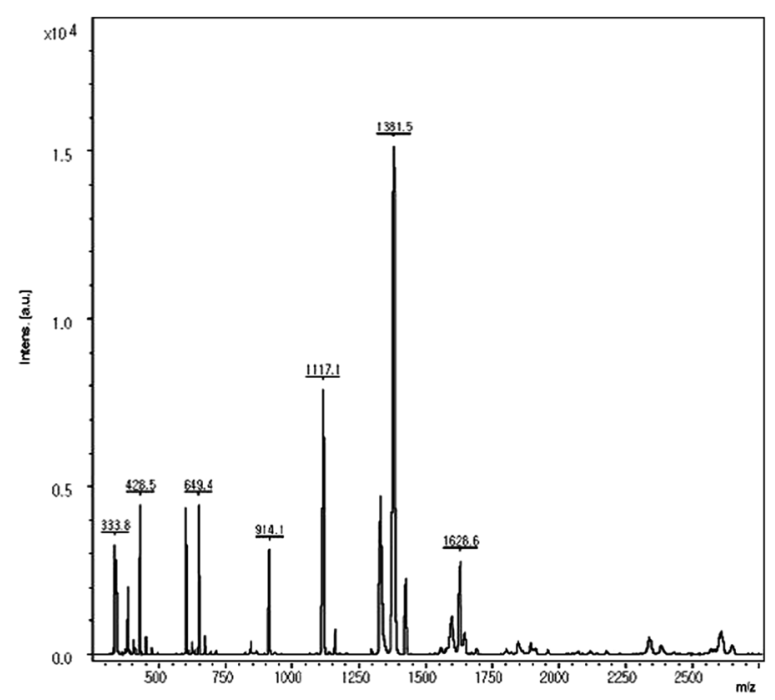

Fig. 3 Mass spectra of the tetramer of $\mathrm{K}_{\mathrm{ir}} 3.1$ cytoplasmic domain from the MALDI set-up shows the peptide fragments of the protein. $K_{i r}$ inward-rectifier potassium ion channel, MALDI matrix-assisted laser desorption/ ionization

\section{MATERIALS AND METHODS}

The $0.8 \mathrm{~nm}$ negatively charged gold nanoparticles were purchased from Nanoprobes, Inc (New York, NY, USA). The ionic bond was induced by vortexing two samples with different concentrations of positively charged spermidine (i.e., $10 \mathrm{mM}$ and
$100 \mathrm{nM}), 1 \mathrm{mg}$ of meso-2.3-dimercaptosuccinic acid (DMSA) powder, and $50 \mathrm{nM}$ of negatively charged gold nanoparticles for approximately $15 \mathrm{~min}$ followed by mixing with a pipette for 15 min. The negatively charged $\mathrm{CoO}-$ particles were individually coated with a thin film of three nanoparticle molecules with DMSA, each bound to one $\mathrm{NH}_{2}$ and two $\mathrm{NH}_{1}$ spermidine molecules (Supplementary video clip). The spermidine hydroxide solution and the DMSA were obtained from Sigma Aldrich (St. Louis, MO, USA). Undecagold has a core of 11 gold atoms only $0.8 \mathrm{~nm}$ in diameter and is ideal for ultra-high-resolution EM work such as cryo-EM, scanning transmission EM. In this study, we present the structure, obtained by single particle analysis with cryoEM of the cytoplasmic $K_{i r}$ domain containing undeca-gold inside the complex (Supplementary Figs. 1, 2). Undeca-gold binding occurs at the outer end of the G-loop [11]. Purified protein solutions were diluted to $10 \mu \mathrm{g} \mathrm{mL}^{-1}$ in a buffer solution containing $20 \mathrm{Mm}$ Tris- $\mathrm{HCl}$ (pH 8.0), $100 \mathrm{mM}$ $\mathrm{NaCl}$, and the corresponding detergent. A diluted protein solution of the cytoplsmic domain of the $K_{i r}$ channel was added at a volume ratio of 1:10 to reach a concentration of 
$\sim 5 \mu \mathrm{g} \mathrm{mL}^{-1}$. Protein complexes were adsorbed for $1 \mathrm{~min}$ onto glow-discharged, 400 mesh carbon-coated grids. The grids were washed with four drops of distilled $\mathrm{H}_{2} \mathrm{O}$. Micrographs were taken at a low dose on a JEM-2100 operated at $120 \mathrm{kV}$ (JEOL Inc, Peabody, MA 01960, USA). Tilt pairs were recorded at $0^{\circ}$ and $45^{\circ}$ or $0^{\circ}$ and $60^{\circ}$, at a nominal magnification of $69000 \times$ on a GatanUltrascan 4 k CCD (Gatan Inc., Pleasanton, CA 94588, USA) [12].

\section{RESULTS AND DISCUSSION}

Spermidine-0.8 nm gold nanoparticles complexes, which is not determined by a transmission EM (TEM) of JEM-2100 (Figs. 4, 5, 6) with energy dispersive X-ray spectroscopy (EDS), surface-coated with DMSA (Figs. 7, 8), have been successfully used to produce a high signal in TEM images in the ion pore or surrounding tetramer components.

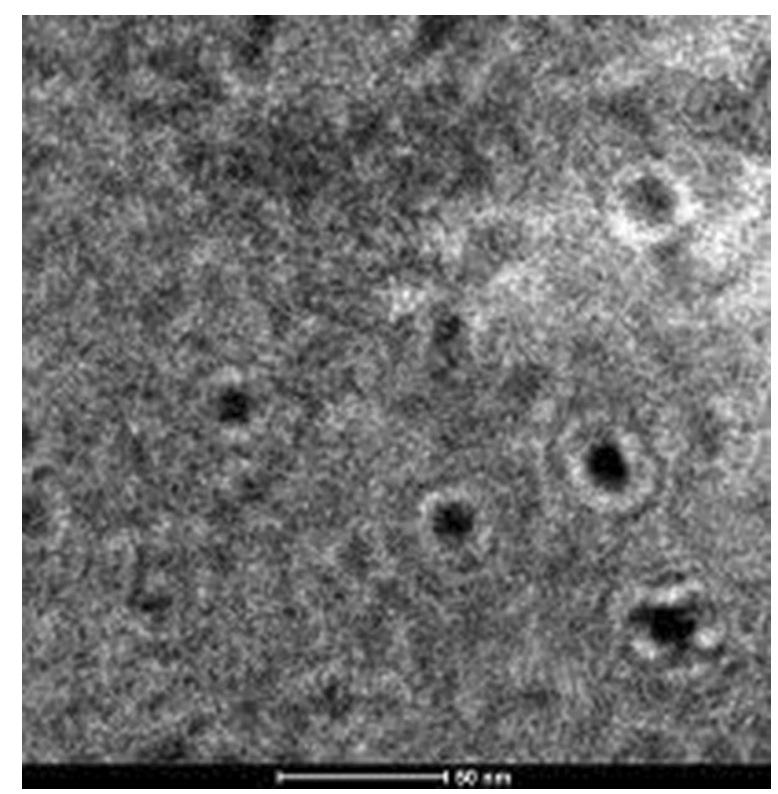

Fig. 4 Treated by gold nanoparticles: single particle analysis with cryoEM shows the cytoplasmic $\mathrm{K}_{\mathrm{ir}}$ domain containing undeca-gold inside the complex
Dimercaptosuccinic acid can form chelates with gold nanoparticles via the two sulfur atoms. DMSA is water soluble with extracellular distribution and cannot penetrate the lipid bilayer, but is able enter to the cytoplasmic domain of $\mathrm{K}_{\mathrm{ir}}$ ion pore accompanied by spermidine molecules, already coated by the gold nanoparticles [13]. Moreover, in atomic force microscope observations, the point less than $0.8 \mathrm{~nm}$ cannot be counted as the gold nanoparticles because of the substrate roughness originating from the natural convex point. Evidence of the existence of gold nanoparticles in the ion pore interaction has been supported by high density surface-coated with DMSA in TEM images [14].

Energy dispersive X-ray spectroscopy was also used to confirm the presence of the gold deposits in the cytoplasmic domain of the $\mathrm{K}_{\mathrm{ir}}$ receptor (Figs. 9, 10, 11). X-ray photoelectron spectroscopy measurements were performed using an ultrahigh vacuum chamber with a base pressure below $5-10^{-9}$ Torr. XPS data was collected using an X-ray photoelectron spectrometer PHI 5400 (Physical Electronics) with a nominal energy resolution of $0.7 \mathrm{eV}$. Spectra were acquired using a photon beam of $1486.6 \mathrm{eV}$, selected from a conventional (nonmonochromatic) $\mathrm{Al} / \mathrm{Mg}$ dual-anode X-ray source. Data was collected at room temperature under vacuum, and samples were analyzed as soon as they were prepared, without any extra cleaning procedure. The EDS spectrum of the receptors containing the gold nanoparticles indicates the presence of $\mathrm{C}$ and $\mathrm{O}$ in the receptor molecules. The small gold peak evidenced in the EDS spectrum confirms that a validated amount of the $0.8 \mathrm{~nm}$ gold nanoparticle is present in the ion pore of the $\mathrm{K}_{\mathrm{ir}}$ channels [15].

Gold nanoparticles $(0.8 \mathrm{~nm})$ belonging to a new class of ion channel inhibitors directly 


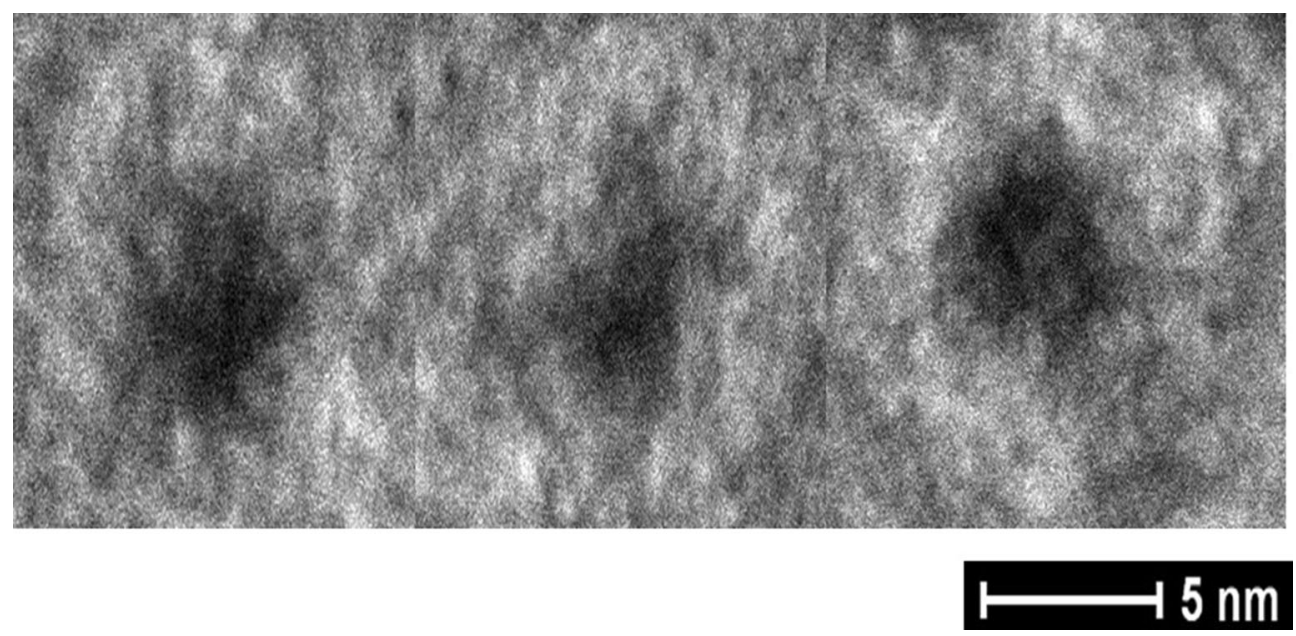

Fig. 5 Two-dimensional TEM images show the tetramer of $\mathrm{K}_{\mathrm{ir}} 3.1$ cytoplasmic domain with dilated lumen of the ion pore by gold nanoparticles. TEM transmission electron microscopy, $K_{i r}$ inward-rectifier potassium ion channel

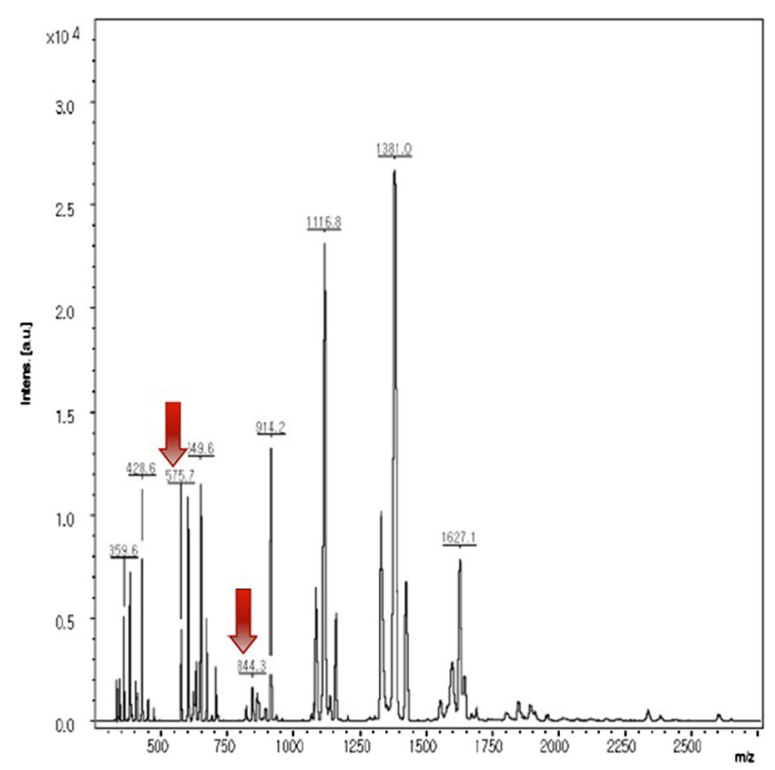

Fig. 6 Mass spectra of tetramer of $\mathrm{K}_{\mathrm{ir}} 3.1$ cytoplasmic domain from the MALDI set-up shows the peptide fragments of the protein containing gold peaks (red arrow). $K_{i r}$ inward-rectifier potassium ion channel, MALDI matrix-assisted laser desorption/ionization

block the human $\mathrm{K}_{\mathrm{ir}}$ channel $\mathrm{I}(\mathrm{KAch})$ when accompanied by the antagonist spermidine. Blocking of the I(KAch) channel by the gold nanoparticle-spermidine complex has been

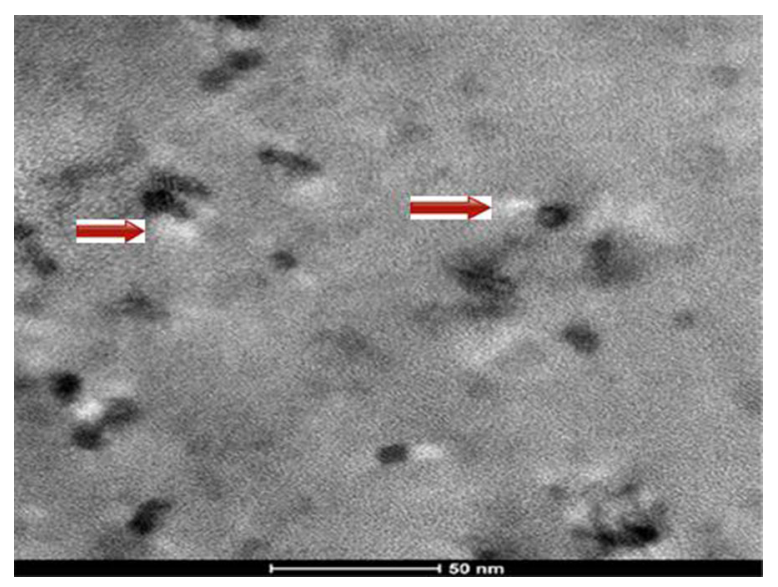

Fig. 7 Treated by gold nanoparticles coating with DMSA-spermidine complex. DMSA meso-2.3-dimercaptosuccinic acid

shown to occur in atrial cardiomyocytes. A reduced $\mathrm{K}^{+}$current delays the repolarization of the complex in patients with atrial fibrillation (AF) [16].

This complex is a new class of three anti-arrhythmic agents that may potentially treat AF [17]. The complex is designed to be a selective I(KAch) blocker in contrast to multiple class 1 and 3 anti-arrhythmic agents with less proarrhythmic potential [18]. 

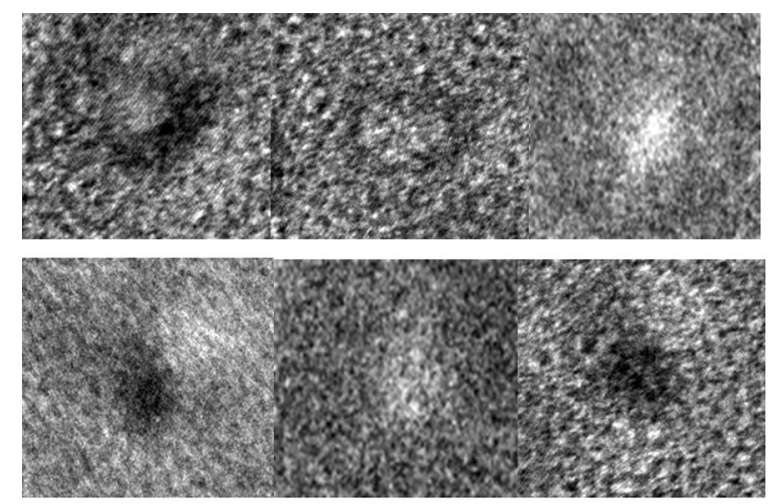

$\longmapsto 5 \mathrm{~nm}$

Fig. 8 Two-dimensional TEM images of tetramer of $\mathrm{K}_{\mathrm{ir}} 3.1$ cytoplasmic domain after treating with undecagold cating with DMSA-spermidine complex shows the hyperdense DMSA coating in the ion pore or adjacent tetramer. TEM transmission electron microscopy, $K_{i r}$ inward-rectifier potassium ion channel, DMSA meso-2.3-dimercaptosuccinic acid

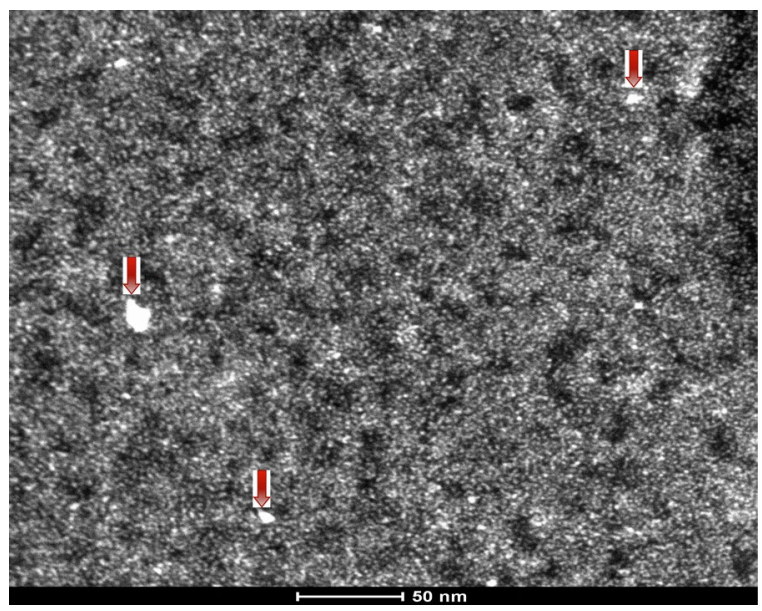

Fig. 9 EDS by STEM of the cytoplasmic domain of the receptor treated by gold nanoparticles: transmission EM (TEM) with surface-coated with DMSA have been successfully used to produce a high signal in TEM images in the ion pore or surrounding tetramer components. EDS energy dispersive $\mathrm{X}$-ray spectroscopy, STEM scanning transmission electron microscopy

A limitation of this study was that the authors could not identify the 3-D images of the gold nanoparticles in the ion pore because of technical limitations.

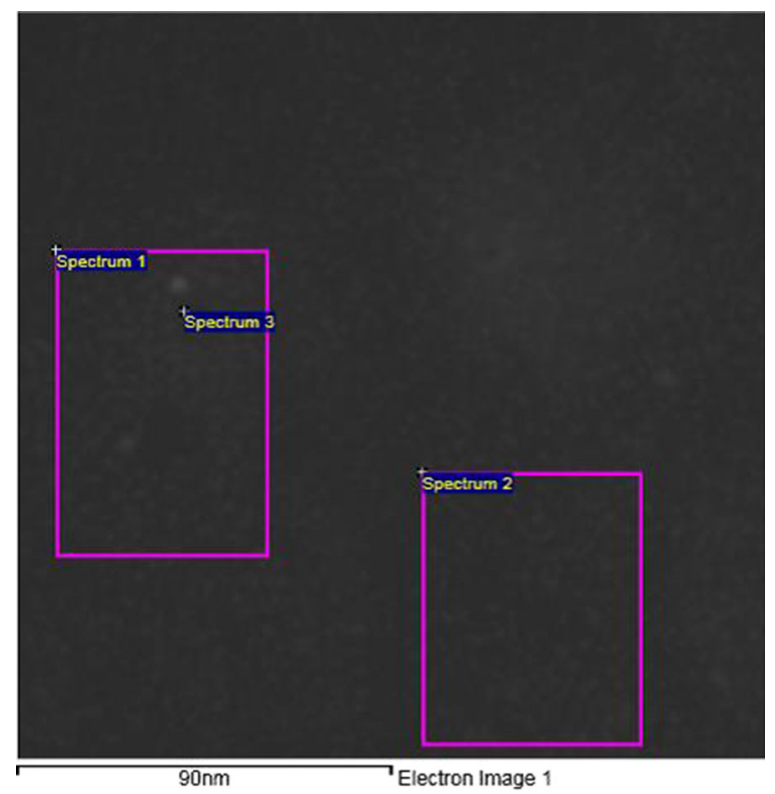

Fig. 10 Two-dimensional STEM images for the EDS shows hyperdense gold nanoparticle (red arrow) in the lumens of the tetramer of the cytoplasmic domain. STEM scanning transmission electron microscopy, EDS energy dispersive X-ray spectroscopy

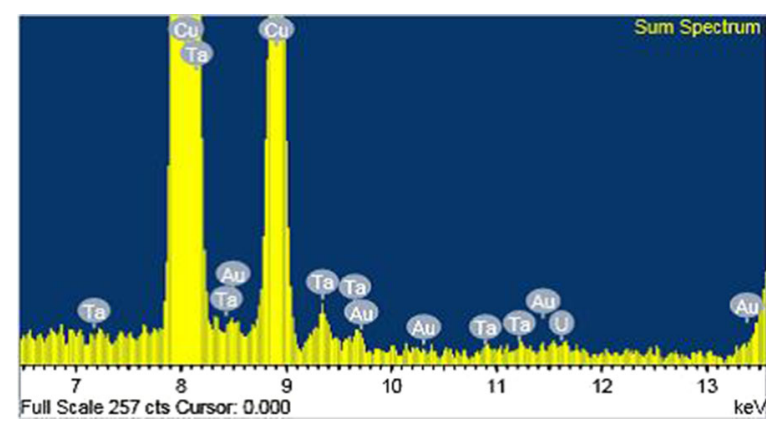

Fig. 11 The EDS spectrum of the receptors containing the gold nanoparticles in it indicates the presence of $\mathrm{C}$ and $\mathrm{O}$ from the receptor molecules. The small gold peak evident in the EDS spectrum confirms that a validated amount of the $0.8 \mathrm{~nm}$ gold nanoparticle is present in the ion pore of $\mathrm{K}_{\mathrm{ir}}$ channels. EDS energy dispersive X-ray spectroscopy, $K_{i r}$ inward-rectifier potassium ion channel

\section{CONCLUSION}

In conclusion, we could identify undeca-gold in the ion pore of the $\mathrm{K}_{\mathrm{ir}} 3.1$ channel in order to 
clarify its direct blocking effect in the $\mathrm{K}_{\mathrm{ir}}$ ion pore by undecagold.

\section{ACKNOWLEDGMENTS}

No funding or sponsorship was received for this study or publication of this article. All named authors meet the International Committee of Medical Journal Editors (ICMJE) criteria for authorship for this manuscript, take responsibility for the integrity of the work as a whole, and have given final approval for the version to be published. We would like to thank LugenSci Inc., Seoul, Korea, IL for purification experiments of the cytoplasmic domain of the receptor presented in this paper. Financial support is acknowledged from the Research Center Program (CA1208) of Institute for Basic Science (IBS) (IBS-R013-D1-2015-a00), Republic of Korea.

Disclosures. Chur Chin and Yu Shin Park have nothing to disclose.

Compliance with ethics guidelines. This article does not contain any new studies with human or animal subjects performed by any of the authors.

Open Access. This article is distributed under the terms of the Creative Commons Attribution-NonCommercial 4.0 International License (http://creativecommons.org/licenses/ by-nc/4.0/), which permits any noncommercial use, distribution, and reproduction in any medium, provided you give appropriate credit to the original author(s) and the source, provide a link to the Creative Commons license, and indicate if changes were made.

\section{REFERENCES}

1. Nicholas CG, Makhina EN, Pearson WL, Sha Q, Lopatin AN. Inward rectification and implications for cardiac excitability. Circ Res. 1996;78:1-7.

2. Wilczewska AZ, Niemirowicz K, Markiewicz KH, Car H. Nanoparticles as drug delivery systems. Pharmacol Rep. 2012;64:1020-37.

3. Chin C, Kim IK, Lim DY, Kim KS, Lee HA, et al. Gold nanoparticls-choline complexes can block nicotinic acetylcholine receptors. Int J Nanomed. 2010;5:315-21.

4. Leifert A, Pan Y, Kinkeldey A, Schiefer F, Setzler J, Scheel $\mathrm{O}$, et al. Differential hERG ion channel activity of ultrasmall gold nanoparticles. PNAS. 2013;110:8004-9.

5. Chin C. Gold nanoparticle-spermidine complex blocks the inward rectifier potassium channel. Am J Cardiovasc Dis. 2014;4:34-46.

6. Craven SE, Bredt DS. PDZ proteins organize synaptic signaling pathways. Cell. 1998;93:495-8.

7. Krumm BE, White JF, Shah P, Grisshaamer R. Strutural prequisites for G-protein by the neurotensin receptor. Nat Commun. 2015;24:7895.

8. Pegan S, Arrabit C, Zhou W, Kwiatkowski W, Collins A, Slesinger PA, Choe S. Cytoplasmic domain structures of $\mathrm{K}_{\mathrm{ir}} 2.1$ and $\mathrm{K}_{\mathrm{ir}} 3.1$ show sites for modulating gating and rectification. Nat Neurosci. 2005;8:278-87.

9. Osawa M, Yokogawa M, Muramatsu T, Kimura T, Mase Y, Shimada I. Evidence for the direct interaction of spermine with the inwardly rectifying potassium channel. J Biol Chem. 2009;284:26117-26.

10. Whorton MR, MacKinnon R. X-ray structure of the mammalian GIRK2- $\beta \gamma$ G-protein complex. Nature. 2013;498:190-7.

11. Nishida $M$, Cadene $M$, Chait BT, MacKinnon R. Crystal structure of a $\mathrm{K}_{\mathrm{ir}} 3.1$-prokaryotic $\mathrm{K}_{\mathrm{ir}}$ channel chimera. EMBO J. 2007;26:4005-15.

12. Piana S, Lindorff-Larsen K, Shaw DE. Atomic-level description of ubiquitin folding. PNAS. 2013;15:5915-20.

13. Zhou ZH. Atomic resolution cryo electron microscopy of macromolecular complexes. Adv Protein Chem Struct Biol. 2011;82:1-35. 
14. Aposhian HV, Aposhian MW. Meso-2,3-dimercaptosuccinic acid: chemical, pharmacological and toxicological properties of an orally effective metal chelating agent. Annu Rev Pharmcol Toxicol. 1990;30:279-306.

15. Liu Y, Wang J. Effects of DMSA-coated $\mathrm{Fe}_{3} \mathrm{O}_{4}$ nanoparticles on the transcriptions of genes related to iron and osmosis homeostasis. Toxicol Sci. 2013;131:521-36.

16. Toby S, Takashi I, David O, Daniela P, Jean MJF, Alex Z. Self-assembly of gold nanoparticles at the surface of amine- and thiol-functionalized boron nitride nanotubes. J Phys Chem C. 2007;111:12992-9.

17. Ju S, Yeo WS. Quantification of proteins on gold nanoparticles by combining MALDI-TOF MS and proteolysis. Nanotechnology. 2012;23:135701.

18. Nattel S. Calcium activated potassium current: a novel ion channel candidate in atrial fibrillation. J Physiol. 2009;587:1385-6. 